\title{
Impact of increasing productivity on work content and psychosocial work characteristics in Chaku-Chaku assembly lines - a follow-up study in a German automotive manufacturing company ${ }^{1}$
}

\author{
José-Alonso Enríquez-Díaz, Daniel Kotzab*, Alina Sytch and Ekkehart Frieling \\ Department of Work and Organizational Psychology, University of Kassel, Heinrich-Plett-Straße 40, 34134 \\ Kassel, Germany
}

\begin{abstract}
The current study aims at evaluating the reorganization of work processes on the basis of studies of three assembly lines in a well known component manufacture of the German automotive industry. It is of particular interest to evaluate the impact of the introduction of Chaku-Chaku assembly lines on the production goals, distribution of activities during one typical work day and psychosocial characteristics of the work environment. Findings indicate that the Chaku-Chaku assembly lines could represent a successful production strategy in order to enhance the output levels of work systems. However, the data show that interviewed assembly workers have spent more time on value added activities than before. The intensive perception of the time spent on main work activities (direct value added activities) and a simultaneous decrease of available discretionary time between work tasks seem to be related to the low level of the reported psychosocial work characteristics.
\end{abstract}

Keywords: Chaku-Chaku assembly concept, work activities, psychosocial work characteristics.

\section{Introduction}

The automotive industry is an economic key sector in every major country of the world. In Europe the German automotive industry is one of the most important branches. In 2009 the number of workplaces amounts to approx. 723.000 employees (manufacture of vehicles, trailers and bodies and parts and accessories) [1]. However, the existing working conditions in many manufacturing shop floor areas are not consistent with the economic and social importance of this branch. Only sometimes, a balance between industrial development and physical and psychological well-being of workers can be reported [2].
Production systems are the organizational approach to run the business of the enterprise in which manufacturing areas are set. [3]. Today, most of the automotive manufacturers and suppliers adopt the Toyota Production System (TPS) as a framework for an integrated production management. Since its introduction, the TPS has experienced many changes and has, at the same time, contributed to changes in the interaction between the worker and his environment. Throughout the last decade, introduced changes are first of all a primary result of the experience of other companies having introduced TPS into their respective work environments. This has lead to a process of alteration and adaptation of some ele-

\footnotetext{
${ }^{1}$ Earlier versions of this article were presented at the 10th International Symposium on Human Factors in Organisational Design and Management (ODAM) in Grahamstown.

*Corresponding author. E-mail: kotzab@uni-kassel.de
} 
ments of TPS. Many companies have taken advantage of this and adapted some TPS-Elements to their real work environments. Secondly, the global competitiveness and the sharp mark situation over the last years has had the automotive global market increase the levels for output, quality and variety of produced vehicles with fewer costs. This phenomenon is accompanied by an expansion of the TPS into a wider sector (e.g.: adoption in the supply change, integration of new technologies, etc.) [4].

Maintaining the human resource policy of TPS, the increased introduction of alternative assembly systems (e.g. Chaku Chaku Assembly Concepts) into the German Automotive industry is striking. ChakuChaku (Japanese: load-load) assembly concepts are cellular assembly systems which imply new characteristics in the job design of assembly workplaces. This way of production, originating in the Japanese electronics industry [5], seeks the rigorous elimination of waste based on the Just-In-Time approach. In this way, the worker mainly deals with the value added production of goods [6].

With regard to this development, it is interesting to observe the growing preference and introduction of Chaku-Chaku assembly cells into the German automotive industry, instead of typical line-based assembly concepts (also called straight assembly lines). In this context, the current study aims at evaluating the effects of performed assembly work in two ChakuChaku assembly lines and compares the results with changes in a typical straight assembly line. Based on the longitudinal methodology for the current study, firstly the authors explore the effects of the introduction of Chaku-Chaku assembly lines on work performance in terms of reached productivity. After this, the authors report the impact of Chaku-Chaku assembly lines on the distribution of time spent by blue-collar workers on different working tasks. Finally, changes in the perception of psychosocial characteristics of the work environment are reported for each studied sample.

\section{Methodology}

The three studied sampled are studied in the framework of a longitudinal analysis which consists of two points of data collection. The use of research methods (see Item 2.2.) are complemented by regular inspection of the workplaces during the time of data collection.

\subsection{Description of samples}

The empirical research takes place in a worldwide component manufacture of the German automotive industry. Each sample is organized according to principles of team work. Each team consists of 8 to 10 workers and a team leader. The company presents a span of control of 30 workers per supervisor. The principal demographic data of the studied samples are described in the following (see Table 1).

\subsubsection{Sample A}

In the production area 30 blue-collar workers are employed. They assemble handbrake levers for personal cars. Here, two independent assembly cells are positioned next to each other. Each assembly cell consists of two workstations which are arranged according to the Chaku-Chaku approach. The components are supplied by an operator (line-filler) from outside of each cell. In each workstation the main assembly tasks are the manual loading of parts for the automatic assembly into the machines. After the automatic start, the assembly worker walks to the next machine in order to repeat this operation. During the time period of investigation this sample is in the start-up phase. The cycle time amounts to $25 \mathrm{sec}$. at the time of second data collection.

\subsubsection{Sample B}

Altogether there are 35 blue-collar workers in this assembly area, where exhaust pipes are produced. The assembly of the single parts (e.g.: catalytic converters, sheet metal parts, pipes) for diesel and gas engines of personal cars are carried out in four assembly cells. Each cell consists of between 1 and 5 workstations arranged according to the Chaku-Chaku assembly concept. Here, each worker loads and unloads single parts along a mostly circular path leading them through several stations. In contrast to sample A, sample B already reaches a steady stable (full production capacity) at the time of the first data collection (pre-intervention) and undergoes changes principally due to improvement measures from CIPWorkshops (Continuous Improvement Process). These are based on the Lean Production philosophy [7] and seek to reduce the scrap levels and eliminate the share of non-value added activities. There is only a minor change in the average cycle time from $50 \mathrm{sec}$. at the time of the first data collection to $49 \mathrm{sec}$. at the time of the second data collection. Furthermore in several workstations, a high noise level ( $>85 \mathrm{dBA})$ results from the operation of engraving machines. 


\subsubsection{Sample $C$}

Around 90 blue-collar workers are employed in the assembly of gearboxes for personal cars. In this sample the assembly parts are arranged in a pallet that is transported by conveyors through the different work stations. During the cycle time, when the pallet remains stationary, every worker performs several assembly tasks (e.g.: main assembly tasks, preassembly tasks, operation of machines or hand-hold tools). During the time of investigation, changes in the workplace design are introduced into this sample. The typical straight assembly line has a cycle time of $85 \mathrm{sec}$. at the time of the first data collection and 74 sec. at the second point of data collection.

Table 1

Main demographic data of the studied samples at the time of the first and second data collection (*The cycle time in sample A varies at the beginning of the start-up phase)

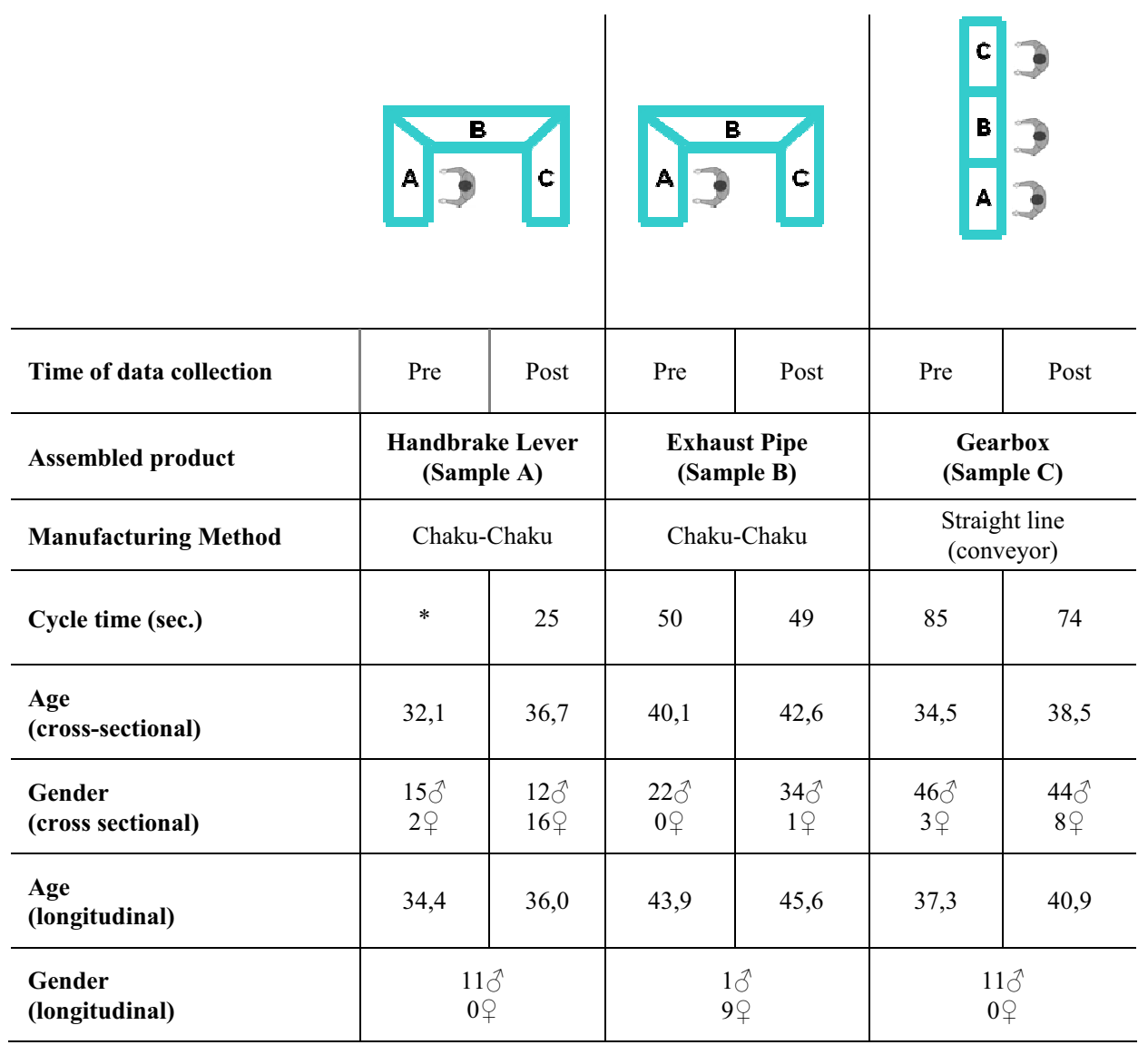

\subsection{Methods}

\subsubsection{Documentation of changes}

Performed organizational and technical changes in work place design are based on improvement measurements of CIP-Workshops. These changes as well as the reached output (productivity) are documented and analyzed from company records.

\subsubsection{Worker activities}

In order to analyze the distribution of worker activities at the time pre and post intervention (first and second point of data collection), five experienced workers of each sample are interviewed. They are asked about the time spent on defined work activities occurring during a typical work shift at the time of the first and second point of data collection. The classification is made according to the "REFA- Clas- 
sification of work process" [8] and implies the time spent on six categories which are consistent with the value-added activities according to TPS [9].

\subsubsection{Psychosocial characteristics}

The subjective perception of psychosocial work characteristics are assessed using the SALSAQuestionnaire [10]. From the 13 scales of SALSA, four scales (15 single items) are related to the psychosocial conditions of the work environment and are reported in this study. Each item is rated according to a five-graded Likert scale ranging from "'hardly ever" to "nearly always".

\section{Results}

\subsection{Documentation of changes}

Firstly, the mayor changes in the technical and organizational work environment are presented. After this, data referring to the development of productivity are shown for each studied sample. As mentioned above, the introduced changes in workplace design are carried out in the framework of a reorganization process according to the internal corporate production system which is based on TPS. Changes in the workplace design can be resumed as presented in the following:

- Sample A: The introduced changes are focused on the improvement of the machine availability. The first point of data collection is characterized by a regular interruption of the work activities due to the low level of machine availability during the ramp-up phase. The technical repair reworks at this point of data collection are carried out by external staff. At the time of the second point of data collection (end of the ramp-up phase) several little maintenance and repair works are taken over by the blue-collar workers in this sample.

- Sample B: The major changes in this area point out an improvement in quality of the assembled products. In this context CIP-Workshops are partly focused on the enhancement of the machine availability. Additionally, work activities related to non-value added motion and waiting of operators are systematically reduced.

- Sample C: In the straight assembly line changes in work place design are introduced in order to eliminate the share of non-value-activities such as waiting times of operators during assembly work. Additionally, assembly parts or tools are positioned as close as possible to the point of assembly so that awkward arm postures and non-value added times are reduced. In order to reduce the workload related to manual material lifting of heavy parts, ergonomic improvements are also introduced in this sample (e.g.: introduction of levelators).

Fig. 1 shows the number of units produced in each sample during a representative time period between the first and second point of data collection. In this context, these figures describe the development of the repetitiveness of the assembly tasks.

A sharp increase in productivity can be observed in sample A (left side of Fig.1). The number of units produced at the end of the ramp-up phase corresponds to a nearly 2.3 fold increase of the figure of the first data collection. Furthermore, sample B presents (right side of Fig. 1) a constant trend in the output development. Moreover, sample $\mathrm{C}$ (at the bottom of Fig.1) presents approx. a 1.2 fold increase in the number of produced gearboxes during the time of study 

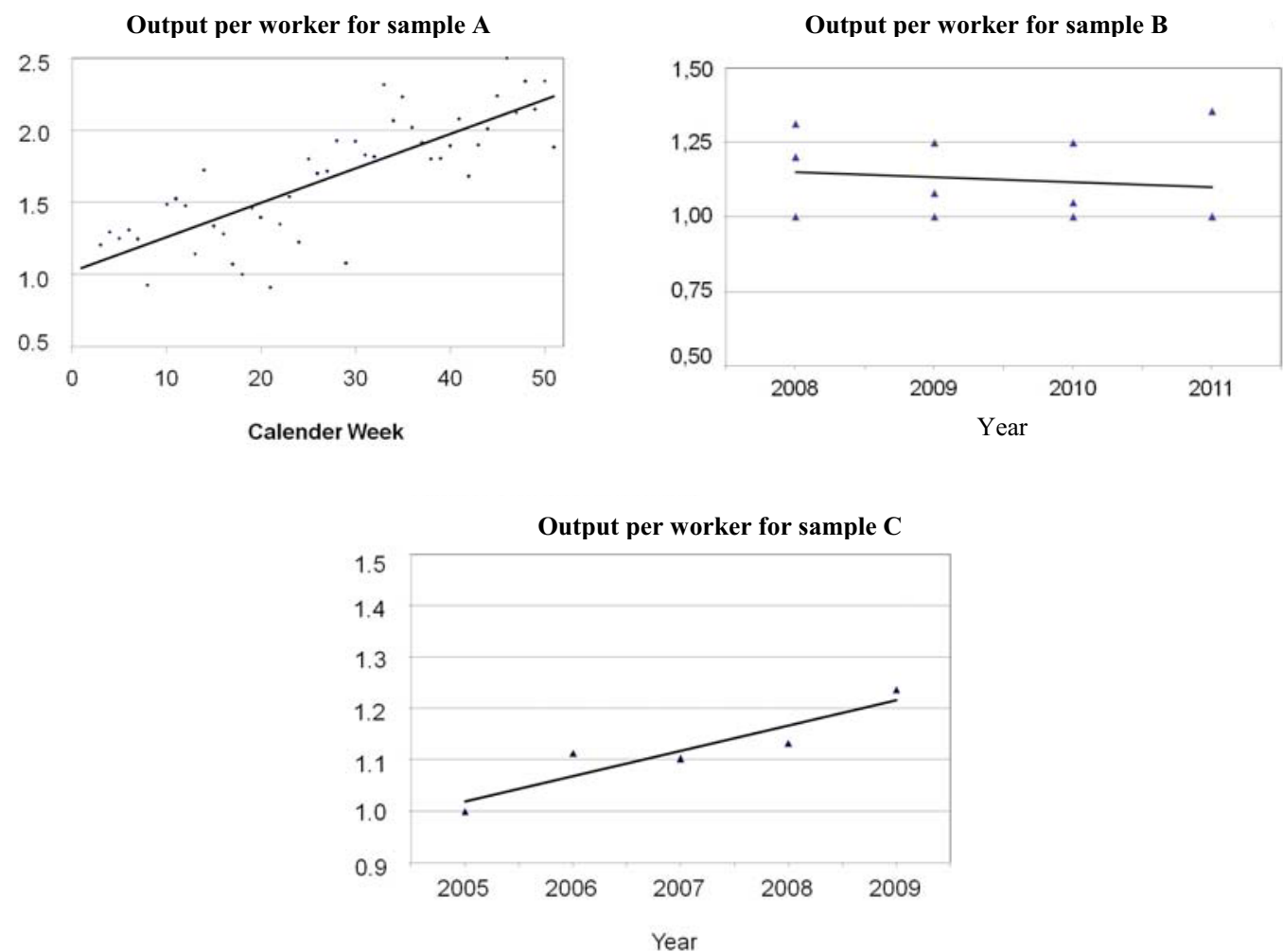

Figure 1: Development of productivity for sample A (Chaku-Chaku), sample B (Chaku-Chaku) and sample C (Straight assembly line) during a representative time period within the investigation time.

(The illustrated output has been standardized according to the respective figure at the beginning).

\subsection{Worker activities}

Table 2 shows the changes of the defined work activities at the time pre and post the intervention. As expected, the interviewed workers in sample A report a statically significant increase in the time spent on "direct value added tasks". Furthermore, on the one hand they report spending more time on "supplementary activities" (e.g.: repair tasks and rework) and on the other hand about a decrease in waiting times due to "disturbance related activity interruptions" (e.g.: waiting for machine repair, waiting due to the unavailability of tools).

Unexpected to our assumptions, there is a statically significant increase in the reported time spent on "main activities" in sample B. Moreover, the interviewed workers perceive a decrease in the time spent on "disturbance related activity interruptions". With regard to the perceived changes in work activities in sample $\mathrm{C}$, there is a decrease in the perceived time spent on "indirect value added tasks", as well as in the category "not recognizable/assignable" (e.g.: the category "not recognizable/assignable" (e.g.: unscheduled ergonomic micro-breaks). Furthermore, there is an increase in the time spent on "main activities". However, this difference is not statistically significant.

\subsection{Psychosocial characteristics}

Table 3 shows the results of the cross-sectional and longitudinal analyses of the psychosocial characteristics in the three studied samples. Sample A shows the most extensive level of significant changes. The results reveal a decrease in the perceived "positive social climate" in the cross-sectional analysis. In the same way, this sample shows a reduction in the perceived "employee-centered supervisor behavior". This change in the cross-sectional study can be confirmed by a decreasing trend $(\mathrm{p}<.10)$ in the longitudinal study. The workers in this sample also report about a decrease in the "social support by supervisor" in the cross-sectional analysis and at the same time about a declining trend in the longitudinal study. 
No statistically significant changes of the psychosocial working conditions are found in sample B. The workers questioned in sample $\mathrm{C}$ only report about a significant decrease in the "social support by supervisor" in the cross-sectional analysis. The other three SALSA-subscales do not show any significant changes.

Table 2

Mean and standard deviations (in percent) of worker activities and the required amount of time at the first and second measurement point according to the REFA- Classification of work process $(* \mathrm{p}<.05 ; * * \mathrm{p}<.01)$

\begin{tabular}{|c|c|c|c|c|c|c|c|c|}
\hline \multirow[b]{2}{*}{$\begin{array}{l}\text { Work process type } \\
\text { (According to [8]) }\end{array}$} & \multicolumn{2}{|c|}{ Pre } & Post & Pre & & ost & Pre & Post \\
\hline & \multicolumn{3}{|c|}{$\begin{array}{c}\text { Sample A } \\
(\mathrm{N}=5 \text { Interview.) }\end{array}$} & \multicolumn{3}{|c|}{$\begin{array}{c}\text { Sample B } \\
(\mathrm{N}=5 \text { Interview.) }\end{array}$} & \multicolumn{2}{|c|}{$\begin{array}{c}\text { Sample C } \\
(\mathrm{N}=5 \text { Interview. })\end{array}$} \\
\hline $\begin{array}{l}\text { 1. Main activities } \\
\text { (Direct value added tasks) }\end{array}$ & $\begin{array}{c}40 \\
(3,5 \\
)\end{array}$ & & $\begin{array}{c}61 \\
(4,2)\end{array}$ & $\begin{array}{c}59 \\
(6,5)\end{array}$ & $*$ & $\begin{array}{c}76 \\
(6,5)\end{array}$ & $\begin{array}{c}59 \\
(6,5)\end{array}$ & $\begin{array}{c}67 \\
(6,7)\end{array}$ \\
\hline $\begin{array}{l}\text { 2. Ancillary activities } \\
\text { (Indirect value added task) }\end{array}$ & $\begin{array}{c}15 \\
(9,4 \\
)\end{array}$ & & $\begin{array}{c}11 \\
(4,2)\end{array}$ & $\begin{array}{c}11 \\
(4,2)\end{array}$ & & $\begin{array}{c}7 \\
(2,7)\end{array}$ & $\begin{array}{c}23 \\
(4,5)\end{array}$ & $\begin{array}{c}14 \\
(4,2)\end{array}$ \\
\hline $\begin{array}{l}\text { 3. Supplementary activities } \\
\text { (task not according to working plan) }\end{array}$ & $\begin{array}{c}12 \\
(5,7 \\
)\end{array}$ & * & $\begin{array}{c}20 \\
(5,0)\end{array}$ & $\begin{array}{c}7 \\
(2,7)\end{array}$ & & $\begin{array}{c}8 \\
(2,7)\end{array}$ & $\begin{array}{c}8 \\
(2,7)\end{array}$ & $\begin{array}{c}7 \\
(2,7)\end{array}$ \\
\hline 4. Process related activity interruption & $\begin{array}{c}4 \\
(4,2 \\
) \\
\end{array}$ & & $\begin{array}{c}0 \\
(0,0)\end{array}$ & $\begin{array}{c}4 \\
(4,2)\end{array}$ & & $\begin{array}{c}1 \\
(2,2)\end{array}$ & $\begin{array}{c}1 \\
(2,2)\end{array}$ & $\begin{array}{c}1 \\
(2,2)\end{array}$ \\
\hline $\begin{array}{l}\text { 5. Disturbance related activity Interruption } \\
\text { (task not according to working plan) }\end{array}$ & $\begin{array}{c}24 \\
(5,5 \\
)\end{array}$ & & $\begin{array}{c}6 \\
(2,2)\end{array}$ & $\begin{array}{c}11 \\
(4,2)\end{array}$ & $*$ & $\begin{array}{c}6 \\
(2,2)\end{array}$ & $\begin{array}{c}7 \\
(2,5)\end{array}$ & $\begin{array}{c}10 \\
(3,5)\end{array}$ \\
\hline 6. Not recognizable /not assignable & $\begin{array}{c}5 \\
(3,5 \\
)\end{array}$ & & $\begin{array}{c}2 \\
(2,7)\end{array}$ & $\begin{array}{c}8 \\
(2,7)\end{array}$ & & $\begin{array}{c}2 \\
(2,7)\end{array}$ & $\begin{array}{c}2 \\
(4,5)\end{array}$ & $\begin{array}{cc}* & 1 \\
& (2,2)\end{array}$ \\
\hline
\end{tabular}

Table 3

Pre- and post- means for measures of the psychosocial work characteristics according to the SALSA-Questionnaire, where 1 = "hardly ever" and $5=$ "almost always"' (CS: Cross-sectional; L: Longitudinal; $\left({ }^{+} \mathrm{p}<.10 ;{ }^{*} \mathrm{p}<.05 ; * * \mathrm{p}<.01\right)$.

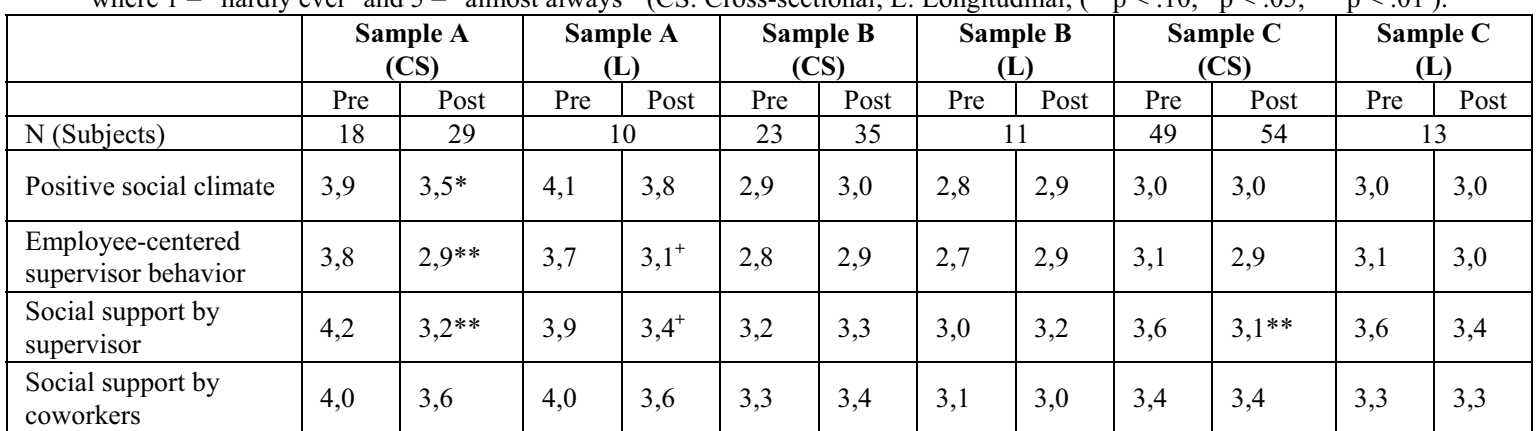




\section{Discussion}

The results in sample A indicate that the increased output of produced handbrake levers is reflected in the rise of the perceived time spent on "main activities" and in the reduction of "disturbance related activity interruption". As expected, the time spent on "supplementary activities" (small repair works) rises at the second time of data collection due to the fact that the qualified blue-collar workers have to maintain the machines by themselves. All together, this seems to be related to the worsening of most of the psychosocial characteristics of the SALSA. Particularly the supporting social characteristic of the supervisor are perceived less intensively.

Although there is not any significant change in output during the time of research in sample B, the time spent on "direct value added task" rises significantly. Thereby, the time spent on waiting due to "disturbance related activity interruptions" decreases. This might be related to the fact that the changes in the workplace design, which were introduced in order to improve the quality of the assembled products, are perceived by the workers as an increase in main work activities. Furthermore, although there is the same perceived increase in "direct added values task" as in sample A, in sample B there is no change in the measured psychosocial factors. As expected, the effect of the introduced measurements is reflected, as perceived by the blue-collar workers in sample $\mathrm{C}$, by the decrease of time spent on "indirect value added tasks". Again pressure for production imposed by manager and supervisor are perceived negatively by the workers in this sample.

These results suggest that an enhancement in the productivity of the studied samples in combination with an increasing perception of time spent on "main activities" (direct value added tasks) leads to a drop in the perceived psychosocial work characteristics. The reduction of work interruptions and ergonomic micro-brakes could lead to a reduction in the available time for social interaction between workers and supervisors and therefore provides less opportunities to build up the stress-resistance psychosocial resources available to meet the demands posed by the working tasks. This assumption is supported by the results of sample B and sample C. None of those samples shows a combined effect of both (objective rise of productivity and perceived increase in time spent on "main activities"). In both cases there are no big changes in the perceived psychosocial work characteristics between coworkers. In general it can be assumed that the workers perceive the management's efforts of the introduction of change measures in order to enhance the output levels.

The current study presents a range of limitations. Some of them are mentioned in the following: small groups in the longitudinal analysis, gender differences of sample A compared to sample B and C. Furthermore, social support and employee-centered behavior by the supervisor can be strongly influenced by fluctuations of the supervisor which takes place in all the three samples studied. External factors, such as the economic situation as well as the influence of private situations, also have a major influence on the workers' attitudes towards work activity.

To sum it up, a consequent increase in productivity should be combined with the possibilities to enrich work tasks by keeping social contacts alive (for example with the implementation of ergonomic micro breaks, job-rotation, etc.). In this context the introduction of Chaku-Chaku assembly lines, which are implemented after the no waste policy of the TPS, reduces the level of perceived latitude for activities. These are in turn related to negative changes in the perceived psychosocial work characteristics. Further research is needed in order to study the impact Chaku-Chaku lines have on physical and mental health indicators.

\section{References}

[1] Verband der Automobilindustrie e. V., Jahresbericht 2009 (Annual Report 2009). Frankfurt/Main.

[2] K. Landau and H. Luczak, Ergonomie und Organisation in der Montage. München Hanser, 2001

[3] J. Chacon and M. Hawkins, Case Study: An Effective Production System for the Automotive Industry, 2001. In K. Zandin and H. Maynard (Eds.), In Maynard's Industrial Engineering Handbook (pp. 9.161-9.176). (5th ed.). NJ: McGraw-Hill Professional.

[4] M. Holweg, The genealogy of lean production, Journal of Operations Management 25 (2007) 420-437.

[5] H. Kono, Fundamental Principles and Side-Effects for Effective Manufacturing Revolution. Proceedings of the Fifth Asia Pacific Industrial Engineering and Management Systems-Conference 2004, 23.5.1-23.5.10.

[6] S. Yagyu, Das synchrone Managementsystem: Wegweiser zur Neugestaltung der Produktion auf Grundlage des synchronen Produktionssystems. Landsberg am Lech: miFachverl., 2007

[7] J. P. Womack, D. T. Jones and D. Roos, The machine that changed the world. New York: Rawson, 1990.

[8] REFA, Datenermittlung Band 2. (2nd ed.), Fachbuchverlag Leipzig, 1991 
[9] T. Ohno, Das Toyota-Produktionssystem. Frankfurt/Main: Campus-Verl., 1993

[10] M. Rimann and I. Udris, Subjektive Arbeitsanalyse: Der Fragebogen SALSA. In: Strohm O, Ulich E (eds) Unternehmen arbeitspsychologisch bewerten. vdf Hochschulverlag, Zurich, 1997. 